\title{
How neuroscience and behavioral genetics improve psychiatric assessment: report on a violent murder case
}

\section{Davide Rigoni ${ }^{1}$, Silvia Pellegrini ${ }^{2}$, Veronica Mariotti ${ }^{2}$, Arianna Cozza ${ }^{2}$, Andrea Mechelli ${ }^{3}$, Santo Davide Ferrara ${ }^{4}$, Pietro Pietrini ${ }^{2}$ and Giuseppe Sartori ${ }^{5}$}

\author{
1 Department of Developmental and Socialization Psychology, University of Padua, Padua, Italy \\ 2 Department of Experimental Pathology, MBIE, University of Pisa, Pisa, Italy \\ 3 Department of Psychosis Studies, Institute of Psychiatry, King's College London, UK \\ 4 Department of Legal Medicine, University of Padua, Padua, Italy \\ ${ }^{5}$ Department of General Psychology, University of Padua, Padua, Italy
}

\section{Edited by:}

Carmen Sandi, Ecole Polytechnique

Federale De Lausanne, Switzerland

\section{Reviewed by:}

María I Cordero, Ecole Polytechnique Fédérale de Lausanne, Switzerland

Paolo Frigiio Nichelli, University of

Modena and Reggio Emilia, Italy

\section{*Correspondence:}

Davide Rigoni, Department of

Developmental Psychology and

Socialization, University of Padova, via

Venezia 8, 35131 Padova, Italy.

e-mail: davide.rigoni@unipd.it
Despite the advances in the understanding of neural and genetic foundations of violence, the investigation of the biological bases of a mental disorder is rarely included in psychiatric evaluation of mental insanity. Here we report on a case in which cognitive neuroscience and behavioral genetics methods were applied to a psychiatric forensic evaluation conducted on a young woman, J.F., tried for a violent and impulsive murder. The defendant had a history of multidrug and alcohol abuse and non-forensic clinical evaluation concluded for a diagnosis of borderline personality disorder. We analyzed the defendant's brain structure in order to underlie possible brain structural abnormalities associated with pathological impulsivity. Voxel-based morphometry indexed a reduced gray matter volume in the left prefrontal cortex, in a region specifically associated with response inhibition. Furthermore, J.F.s DNA was genotyped in order to identify genetic polymorphisms associated with various forms of violence and impulsive behavior. Five polymorphisms that are known to be associated with impulsivity, violence, and other severe psychiatric illnesses were identified in J.F.s DNA. Taken together, these data provided evidence for the biological correlates of a mental disorder characterized by high impulsivity and aggressive tendencies. Our claim is that the use of neuroscience and behavioral genetics do not change the rationale underlying the determination of criminal liability, which must be based on a causal link between the mental disorder and the crime. Rather, their use is crucial in providing objective data on the biological bases of a defendant's mental disorder.

Keywords: violence, mental insanity, criminal responsibility, impulsivity, polymorphisms, prefrontal cortex

\section{INTRODUCTION}

Violence is a crucial matter for worldwide societies, especially for the criminal justice systems. Over the last decades, developments in cognitive neuroscience and behavioral genetics have provided new insights into the nature of violent and criminal behavior by identifying genetic and neural correlates of impulsivity, aggressiveness, emotional disturbances, and personality disorders (see Wahlund and Kristiansson, 2009 for a review). Brain imaging methods, such as functional magnetic resonance (fMRI) and positron emission tomography (PET), provided evidence that structural and functional alterations of specific brain regions are associated to the development of various forms of psychiatric diseases and overt antisocial and violent behavior (Raine, 2008; Wahlund and Kristiansson, 2009).

Indeed, the idea that brain impairments may result in a person to become more violent is no longer debated. Since the famous case of Phineas Gage (Harlow, 1848), innumerable empirical studies have investigated the function and the structure of various brain regions associated with criminal and violent behavior (see Mobbs et al., 2007; Raine, 2008; Wahlund and Kristiansson, 2009 for reviews). For instance, neuropsychological data showed that increased aggressiveness and violence may result from damages to various regions of the prefrontal cortex (PFC; Grafman et al., 1996). Neuroimaging studies have demonstrated that impulsivity and aggressiveness are associated with specific damages in the PFC (Aron et al., 2003; Li et al., 2006). Other studies have highlighted neuroanatomical and functional correlates of mental abnormalities that are significantly associated with violence, such as antisocial personality disorder (Raine et al., 2000), psychopathy (Raine et al., 1997), and borderline personality disorder (Herpetz et al., 2001). Taken together, these studies show that specific regions of the brain, particularly within the PFC, are involved in the development of antisocial behavior and in the overt expression of various forms of violence.

Research in behavioral genetics provided strong evidence that specific genetic polymorphisms are risk factors for the development of violence and other forms of psychiatric illnesses (see Züchner et al., 2007 for a review). For example, the low-activity alleles of the monoamine oxidase $\mathrm{A}$ (MAOA) gene have been associated with a significant volume reduction (i.e. $8 \%$ ) in brain regions that are known to be altered in antisocial groups, such as the amygdala, the anterior cingulate cortex, and the orbitofrontal cortex (MeyerLindenberg et al., 2006). MAOA was also found to be implicated in antisocial behavior in both animals (Cases et al., 1995) and humans (Caspi et al., 2002).

The emergence of a new field of research which combines behavioral genetics and cognitive neuroscience, has allowed the relationship between cognitive and behavioral correlates of 
antisocial features, brain impairments and genetic variations (i.e. polymorphic alleles) to be investigated (Raine, 2008). The rationale is that gene alterations result in structural or functional brain abnormalities which in turn affect emotional and cognitive development; deficits in emotional regulation and cognitive performance may in turn confer vulnerability to the development of psychiatric syndromes. This "from-genes-to-brain-to-behavior" approach (Raine, 2008) has provided insight into how specific polymorphisms may lead to brain changes which, in turn, may increase vulnerability to various forms of violent behavior and psychiatric disorders. So far, several genes have been associated with changes in brain development and function that are in turn associated with different psychiatric disorders and/or violent behavior (see Raine, 2008 for a review).

Taken together, these findings are of extreme relevance for a deeper understanding of violence and, therefore, also for the criminal justice system. When a person commits a crime, forensic psychiatrists are asked to assess the defendant for criminal responsibility, that is, for whether or not he or she has to be considered liable for the committed crime. What is crucial to the determination of criminal responsibility, is the evaluation of the mental insanity. More precisely, in criminal trials, the insanity defense is a possible defense by which the defense attorney argues that the defendant should not be held criminally liable for breaking the law, because mentally insane at the time of the commission of the alleged crime. The criterion of mental insanity entails the notion that individuals suffering from a severe mental disorder may not bear the full weight of responsibility for their actions. Although law varies from country to country, most of the Western legal systems require the proof of a causal link between the pathological mental state - i.e. the mental disease - and the criminal behavior. In other words, mental insanity - or diminished responsibility - are proved when the crime is the symptom of an underlying mental disease: in this case, the defendant had a reduced capacity to "do otherwise" due to his or her mental illness. In the Anglo-American legal system, for instance, the McNaughten Rule indicates that for an individual to be found not responsible for the crime he or she committed, his or her mental disorder must render him or her unable to know the nature and quality of the act or that it was wrong. Thus, in short, mental insanity - or diminished responsibility - is proved by a causal link between the committed crime and the mental disease.

Despite criminal justice system's increased attention toward scientific advances in understanding violence, neuroscientific investigations, and behavioral genetic analyses are rarely implemented in the evaluation of criminal responsibility. Typically, expert evaluations aimed at assessing mental insanity include diagnostic procedures (e.g. clinical interviews) that are based on symptoms (e.g. hallucinations and delusions) as they are reported by the defendant. Given that psychiatric symptoms may be easily faked, as they are mostly based on the defendant's verbal report, the "objective evidence" of mental disease is therefore critical in the forensic arena. In other words, neuroscientific and genetic data may provide reliable information as regard the nature of the mental disease. However, it must be stressed that cognitive neuroscience and genetic analysis may not be used to explain the cause of the violent crime, but rather to instrumentally prove a "hard" correlate of the mental disease, which symptoms are causally linked to crime.
Here we present a criminal case studied with cognitive neuroscience and molecular genetics methods. This approach, here we claim, may help in assessing mental insanity and in turn assist Courts in determining the criminal responsibility of defendants. We will report on a forensic case of a young woman, J.F., convicted for a second-degree murder. The full assessment reported hereafter will include: (i) a psychometric assessment of psychiatric symptoms; (ii) a neuropsychological examination; (iii) a morphometric analysis with VBM; (iv) a genetic analysis of J.F.'s DNA, aiming at identifying genetic polymorphisms associated with various forms of violence and antisocial behavior.

\section{MATERIALS AND METHODS}

J.F. was a 24-years-old Swiss-Italian woman charged with murder for smothering to death her newborn child immediately after delivery. She gave birth to a male infant, while alone, in the bathroom of her boyfriend's apartment. According to the prosecutor, J.F. would have impulsively smothered the newborn to death immediately after the childbirth. Then she would have wrapped the body in a towel and hid it inside a suitcase. However, the defendant declared she had no memories of the circumstances of the childbirth. Following police investigations, a charge of a second-degree murder was laid.

Clinically relevant biographical data were collected during the interview with the defendant. Her parents and close friends were also interviewed. Collateral information were gathered from trial transcripts and from Police and Court reports.

She started smoking cigarettes when only 11-years-old and experienced several work-related problems. She had a well documented history of multidrug abuse (e.g. cannabis, cocaine, MDMA, heroin) as well as alcohol abuse since she was 13-years-old. She was mother of another child. Remarkably, at the time of her first pregnancy, when she was 20-years old, she went to the hospital by bike just before delivering the child. She got pregnant after a party and reported that she was intoxicated by alcohol and drugs and that she does not remember who was the father of the child. However, as she did for the first pregnancy, she hid the fact that she was pregnant to others.

She was referred by the defense for a forensic psychiatric evaluation in order to determine a psychiatric diagnosis and criminal responsibility. More precisely, a forensic psychiatric evaluation was requested to determine whether there was substantial evidence that the defendant had an irresistible impulse to commit the crime. Thus, the expert examination was to determine if impaired mental abilities actually caused the crime.

\section{PSYCHIATRIC ASSESSMENT}

A screening for relevant psychiatric conditions was conducted by means of a clinical psychiatric interview and by administration of two standardized tests for personality assessment, the Minnesota Multiphasic Personality Inventory-2 (MMPI-2; Butcher et al., 1989) and the Psychopathic Personality Inventory-Revised (PPI-R; Lilienfeld and Widows, 2005).

The MMPI-2 is the most widely used self-report test for measuring psychopathological and clinically relevant personality traits. Although the 567 true/false MMPI-2 items produce several scales and subscales, here we only report on 10 clinical, 15 content, and 2 supplementary scales (i.e. the MacAndrew Alcoholism ScaleRevised and the Addiction Acknowledgment Scale). 
The PPI-R is a 154 items self-report measure of the personality traits associated with psychopathy (Lilienfeld and Widows, 2005). The respondent is asked to respond using a 4-points scale ranging from 1 (false) to 4 (true). The PPI-R yields an overall score and two factor scores - Self-Centered Impulsivity and Fearless Dominanceas well as scores on the seven content scales - Machiavellian Egocentricity, Social Influence, Coldheartedness, Carefree Nonplanfullness, Fearlessness, Blame Externalization, Rebellious Nonconformity, and Stress Immunity. Raw scores are converted into percentiles (Lilienfeld and Widows, 2005).

\section{NEUROPSYCHOLOGICAL ASSESSMENT}

In order to assess J.F. cognitive functioning, we administered a battery of neuropsychological tests, including a working memory test (WMT; Belleville et al., 1996; Mondini et al., 2003), a long term memory test (LMT; Wechsler, 1945; Mondini et al., 2003), the Trail Making Tests (TMT-A and TMT-B; Reitan, 1958; Mondini et al., 2003), attentive matrices (AM: Spinnler and Tognoni, 1987), the Hayling Test (Burgess and Shallice, 1996), a social cognition task (Blair and Cipolotti, 2000; Prior et al., 2003), and a cognitive estimation task (Della Sala et al., 2003).

The administration of the battery was in accordance with the standard protocols. When not specified otherwise, performance of J.F. was compared to the normative data reported in the original papers and manuals.

\section{BRAIN MORPHOMETRY}

A magnetic resonance imaging (MRI) scan was acquired using a Siemens 1.5 T (Siemens Medical Systems, Erlangen, Germany). To test for possible structural brain abnormalities in J.F., we then used VBM, that is a well-established technique for the characterization of neuroanatomical differences in vivo. In recent years, VBM has been used successfully to identify structural brain deficits in a variety of psychiatric diseases (Mechelli et al., 2005); in the present investigation, this technique was used to test for possible local differences in brain volume between J.F. and a control group. The control group consisted of six female participants (age range 22-26) with no history of psychiatric or neurological diseases. More precisely, we aimed at evaluating whether there were significant reductions in those cortical regions that are known to be affected in poor inhibitory control and impulsivity. Recently, a number of studies (Aron et al., 2003; Li et al., 2006) have shown that these areas include the bilateral inferior and middle frontal gyri, the right cingulated gyrus, and the right inferior occipital gyrus.

The VBM analysis was implemented using Statistical Parametric Mapping 5 software (SPM5) running under Matlab 7.0 (MathWorks, Natick, MA, USA). First, images from J.F. and the six controls were segmented in order to extract gray matter and then normalized to an asymmetric T1-weighted template in Montreal Neurological Institute (MNI) stereotactic space, in a recursive manner. Image segmentation incorporated an intensity non-uniformity correction to account for smooth intensity variations caused by gradient distortions and different positions of cranial structures within the MRI coil (Ashburner and Friston, 2000). The resulting gray and white matter images were finally smoothed with a $12-\mathrm{mm}$ isotropic Gaussian kernel. This smoothing kernel was chosen to compensate for the inexact nature of spatial normalization and to maximize the chance that regional effects are expressed at a spatial scale in which homologies in structural anatomy exist over subjects. After smoothing, each voxel represents the local average amount of gray or white matter in the region. A two-sample $t$ test was performed to identify significant differences between J.F. and the control group, using a statistical threshold of $p<0.05$ after family-wise error (FWE) correction for multiple comparisons across the whole brain. In addition, trends significant at $p<0.001$ uncorrected for multiple comparisons are also reported for completeness. While two-sample $t$ tests are typically performed using data sampled from normally distributed populations, they can also be used to compare an individual subject against a control group by assuming that the patient's value constitutes the mean value of a hypothetical population with a variance equal to that of the control group (see for Mühlau et al., 2009 for review).

\section{GENETIC ANALYSIS}

We investigated whether polymorphisms that are known to be associated with psychiatric conditions and violence could be detected in J.F. The allelic variants indicated below were genotyped:

5HTTLPR - the long/short allele (insertion/deletion of a 44-base pair long sequence) in the promoter of the SCL6A4 gene which codifies the Serotonin transporter (Heils et al., 1996).

- STin2 - VNTR (Variable number (9, 10, or 12) of tandem repeats of a 16-17-base pair long sequence in the intron 2 of SCL6A4 gene (Ogilvie et al., 1996).

rs4680 - Single nucleotide polymorphism (SNP G/A) in the exon 4 of Catecol-O-metiltransferase (COMT) gene causing a non-synonymous amino acid change (Val/Met) at codon 158 (dbSNP http://www.ncbi.nlm.nih.gov/SNP/snp_ref. cgi?rs=4680).

- MAOA-uVNTR - Variable number $(2,3,3.5,4,5,6)$ of tandem repeats of a 30-base pair long sequence in the promoter of Monoamino-ossidase A (MAOA) gene (Sabol et al., 1998)

DRD4-2/11 - Variable number (from 2 to 11) of tandem repeats of a 48-base pair long sequence in the exon 3 of the gene which codifies the dopaminergic receptor D4 (Lichter et al., 1993).

DNA was extracted from $400 \mu$ l of J.F.'s whole blood by the nucleic acid automatic extractor Maxwell 16 (Promega), solubilized in TE (Tris- $\mathrm{HCl} 10 \mathrm{mM} \mathrm{pH} \mathrm{8,} \mathrm{EDTA} 1 \mathrm{mM}$ ), and stored at $-20^{\circ} \mathrm{C}$. Genotyping was performed by PCR amplification of the sequences containing the allelic variants.

PCR products were visualized on 3\% ethidium bromide stained agarose gel and sequenced by ABI Prism 310 Genetic Analyzer (Applied Biosystem).

\section{RESULTS}

\section{PSYCHIATRIC ASSESSMENT}

Significant scores on MMPI-2 and PPI-R are reported in Table 1. Both the protocols can be considered valid and thus be interpreted, as the MMPI-2 and PPI-R validity scales fall within the normal range. 
Table 1 | Scores of clinical interest in J.F's MMPI-2 and PPI-R profiles.

\begin{tabular}{|c|c|c|c|}
\hline MMPI-2 scales & Raw scores & T-scores & Clinical descriptors \\
\hline Depression & 31 & 68 & Low self-esteem, unhappiness, apathy, dysphoric mood, and depression \\
\hline Psychopathic deviate & 37 & 88 & $\begin{array}{l}\text { Antisocial personality traits, illegal behavior, social alienation, sexual-related } \\
\text { problems, unhappiness, unreliability, problems at work }\end{array}$ \\
\hline Anxiety & 18 & 76 & Anxiety-related symptoms \\
\hline Low self-esteem & 14 & 70 & Tendency to have a negative idea of the self, negative feelings about the self \\
\hline MacAndrew alcoholism-Revised & 26 & 71 & Drug/alcohol dependence \\
\hline Addiction Acknowledgment & 4 & 68 & Acknowledgment of severe drug/alcohol related problems \\
\hline PPI-R scales & Raw scores & Percentile & Clinical descriptor \\
\hline Carefree non-planfulness & 47 & $>99$ & Tendency to act impulsively, before thinking, failure to learn from one's mistakes \\
\hline
\end{tabular}

The administration of the MMPI-2 provided extensive data on J.F.'s psychopathological and personality profile, which is mainly characterized by antisocial features such as history of illegal behavior, sensation seeking, antisocial personality traits, impulsivity, familial conflict, lack of sensitivity, rejection of conventional standards, and poor response to threatening situations, as well as a non-chalant lack of forethought and a willingness to forgo careful considerations of alternative solutions to the problem. These findings align with the information gathered from the clinical psychiatric interview, interviews with her parents, and from history files.

\section{NEUROPSYCHOLOGICAL ASSESSMENT}

Results obtained by J.F. to the neuropsychological battery are reported in Table 2.

J.F. scored very low on the Hayling test (Burgess and Shallice, 1996), that is intended to measure one's ability to inhibit a prominent response. The attribution of emotional states such as embarrassment and anger to the others, and the ability to identify the violation of social norms, as measured by the Emotion attribution task and the Social situation task (Blair and Cipolotti, 2000; Prior et al., 2003), respectively, were greatly impaired.

\section{BRAIN MORPHOMETRY}

The VBM analysis revealed reduced gray matter volume in the left PFC in J.F. relative to the control group. The strongest effects were detected in the left middle frontal gyrus (co-ordinates: $x=-33$ $y=59 z=14 ; z$-score: $5.64 ; p<0.05$ corrected for multiple comparisons; Figure 1) and the left superior frontal gyrus (co-ordinates: $x=-12 y=60 z=15 ; z$-score: $4.92 ; p<0.05$ corrected for multiple comparisons; Figure 2). In these regions, J.F.'s gray matter was lower than any of the other participants' gray matter. When lowering the statistical threshold to $p<0.001$ (uncorrected), trends were also detected in the lateral temporal cortex and superior occipital cortex (Figures 1 and 2). There were no regions where gray matter volume was significantly greater in J.F. relative to the control group, even when lowering the statistical threshold to $p<0.001$ uncorrected.

\section{GENETIC ANALYSIS}

Five polymorphisms in four genes were genotyped: MAOA-uVNTR, 5HTTLPR (SCL6A4), STin2 (SCL6A4), COMT-rs4680, DRD4-2/11.
In Figure 3 the electrophoretic patterns of the PCR products amplified from J.F.'s DNA is shown. The right length of each fragment was confirmed by direct sequencing.

The COMT-rs4680 genotype was revealed as A/A (Met/Met) after sequencing the PCR product (Figure 4).

The genotypes identified in J.F.'s DNA are summarized in Table 3.

\section{DISCUSSION}

Despite the recent advances in the understanding of biological underpinnings of violence, the implementation of cognitive neuroscience and molecular genetics within the criminal responsibility assessment is at the center of a harsh debate. Part of the skepticism may arise from the idea that neuroscience and behavioral genetics could be used to excuse criminals: their brains and genes made them do it!

Here we propose that these methods should not to be used to provide a causal link between the brain or the genes and criminal behavior. In most Western criminal justice systems, mental insanity pleas require that the crime is causally linked to a pathological mental state that prevent the defendant to "do otherwise". Neuroscience and genetic methods cannot be used to provide a causal link between the mental illness and the crime. Rather, they should be used to obtain a more "objective description" of the defendant's mental disease by providing evidence that the disease has "hard" biological bases. This is particularly important given that psychiatric symptoms may be easily faked as they are mostly based on the defendant's verbal report. Moreover, it has been shown elsewhere (Miller et al., 2001) that traditional psychiatric interviews have unsatisfactory inter-rater concordance. Therefore, providing objective evidence on the biological collates of the "disease of the mind" may be an important logical step for improving accuracy in the evaluation of mental insanity and diminished responsibility.

We implemented here a "from-genes-to-brain-to-behavior" (Raine, 2008) approach to the expert evaluation of a young woman, J.F., tried for smothering her newborn child to death. The evaluation included psychiatric assessment, neuropsychological testing, morphometric brain imaging and molecular genetic analysis. At behavioral level, the defendant showed a severe personality disorder - that can be expressed in terms of borderline personality disorder - a history of multidrug abuse, pathological 
Table 2 | J.F's scores on neuropsychological tests were compared to normative data of each test.

\begin{tabular}{|c|c|c|c|c|c|}
\hline \multirow[t]{2}{*}{ Test } & \multirow[t]{2}{*}{ J.F. scores } & \multicolumn{3}{|c|}{ Normative data } & \multirow[t]{2}{*}{ Descriptor } \\
\hline & & Mean & SD & $z$-value & \\
\hline \multicolumn{6}{|c|}{ WORKING MEMORY WITH INTERFERENCETASK (S) } \\
\hline 30 & $8 / 9$ & 7.32 & 1.46 & 0.47 & Working memory \\
\hline \multicolumn{6}{|l|}{ LONG TERM MEMORYTASK } \\
\hline TMT-A & $33 \mathrm{~s}$ & 31.45 & 10.55 & -0.15 & $\begin{array}{l}\text { Visual and spatial search Selective } \\
\text { attention Task switching }\end{array}$ \\
\hline TMT-B & $127 \mathrm{~s}$ & 9041 & 28.92 & -127 & \\
\hline Attentive matrices & 52.75 & 53.54 & 676 & -012 & Visual selective attention \\
\hline \multicolumn{6}{|l|}{ HAYLING TEST } \\
\hline \multicolumn{6}{|l|}{ EMOTION ATTRIBUTION TASK } \\
\hline Sadness & $9 / 10$ & 8 & 1.2 & 0.83 & Recognition of sadness \\
\hline Fear & $8 / 10$ & 8.94 & 0.95 & -0.99 & Recognition of fear \\
\hline Embarrassment & $4 / 12$ & 9.85 & 1.7 & -3.44 & $\begin{array}{l}\text { Unable to recognize } \\
\text { embarrassment in others }\end{array}$ \\
\hline Disgust & $3 / 3$ & 283 & 0.39 & 0.44 & Recognition of disgust \\
\hline Happiness & $10 / 10$ & 10 & 0 & 0 & Recognition of happiness \\
\hline Anger & $5 / 10$ & 8.19 & 1.25 & -2.55 & $\begin{array}{l}\text { Unable to recognize } \\
\text { anger in others }\end{array}$ \\
\hline Envy & $3 / 3$ & 2.13 & 0.88 & 0.99 & Recognition of envy \\
\hline Seriousness conventional transgressions & $36 / 60$ & 38.65 & 10.67 & -0.25 & \multirow{3}{*}{$\begin{array}{l}\text { Moral thinking } \\
\text { Ability to evaluate moral and } \\
\text { conventional transgressions }\end{array}$} \\
\hline $\begin{array}{l}\text { Moral transgressions non-permissible in } \\
\text { the absence of rules }\end{array}$ & $12 / 12$ & 11.73 & 0.95 & 0.28 & \\
\hline $\begin{array}{l}\text { Conventional transgressions } \\
\text { non-permissible in the absence of rules }\end{array}$ & $10 / 12$ & 8.92 & 2.67 & 0.4 & \\
\hline \multicolumn{6}{|l|}{ SOCIAL SITUATIONTASK } \\
\hline Normative situations & $15 / 15$ & 14.3 & 0.81 & 0.86 & Ability to evaluate social norms \\
\hline Violations of norms & $20 / 25$ & 2405 & 1.09 & -3.72 & $\begin{array}{l}\text { Unable to recognize behaviors } \\
\text { that violate social norms }\end{array}$ \\
\hline Appropriateness score & $58 / 75$ & 53.29 & 7.04 & 0.67 & $\begin{array}{l}\text { Ability to evaluate appropriateness } \\
\text { of behavior in social contexts }\end{array}$ \\
\hline \multicolumn{6}{|l|}{ CET } \\
\hline Absolute errors & $15 / 42$ & 12.16 & 3.31 & 0.86 & Reasoning and self monitoring \\
\hline Bizarre estimates & $2 / 21$ & 1.79 & 1.47 & 0.14 & Absence of bizarre estimates \\
\hline
\end{tabular}

Bold z-values indicate tests in which J.F. performed significantly below controls (i.e., more than 1.5 standard deviations below the mean value of the control group).

impulsivity, high sensation-seeking, impaired behavioral control, functions such as working memory and long-term memory, visual poor understanding of others' emotional state, and a lack of planning ability. However, she did not show impairments in cognitive and selective attention, theory of mind, abstract reasoning, and self-monitoring. Taken together, all these data indicated that J.F. 

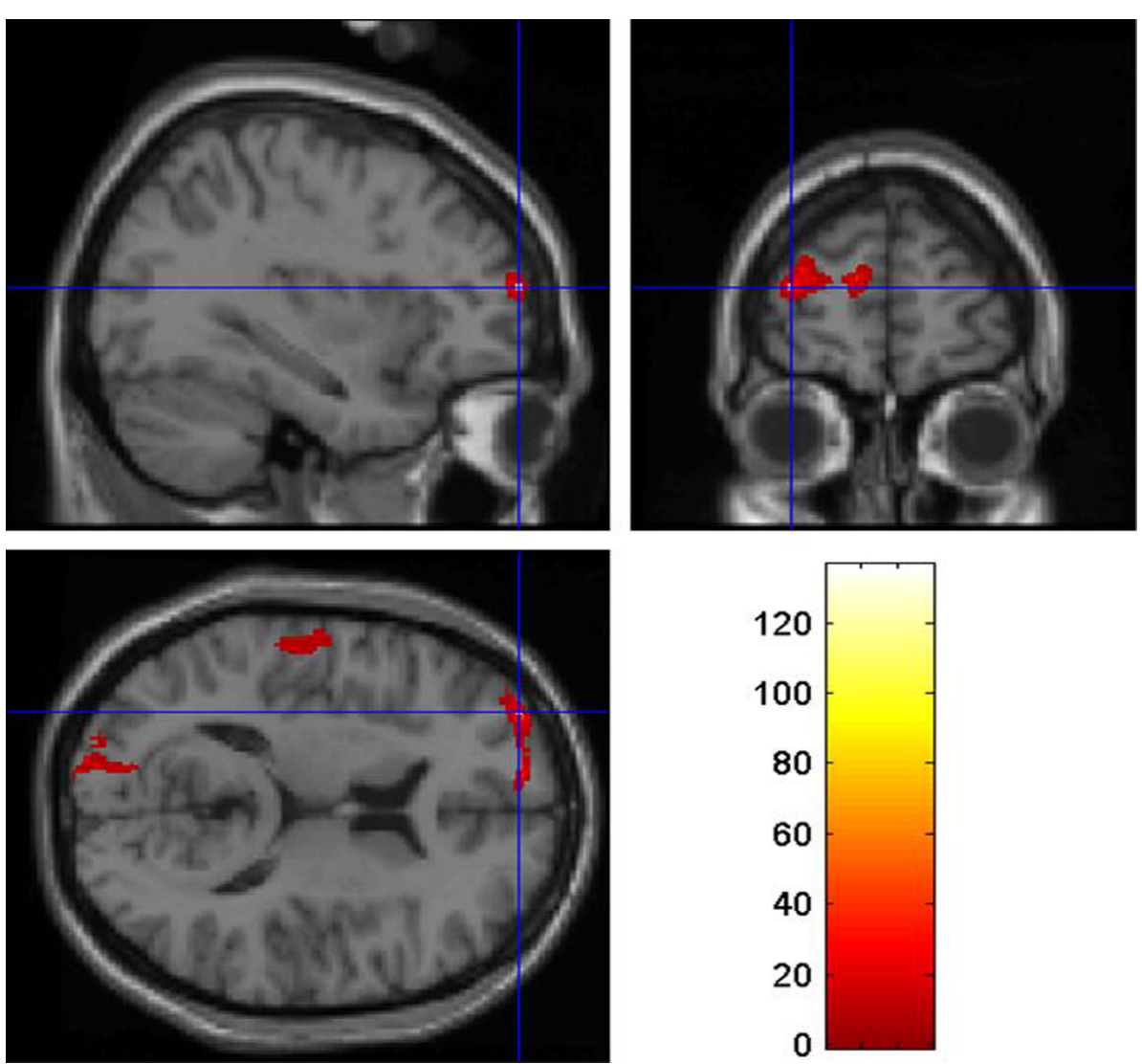

FIGURE 1 | Region of the left middle frontal gyrus showing reduced gray matter density in JF relative to healthy controls, at $p<0.05$ (corrected for multiple comparisons).

suffered from a behavioral syndrome mainly characterized by high impulsivity, poor behavioral control, emotional disorder, and high sensation seeking.

Crucially, the symptoms identified in J.F. showed that she has a reduced capacity to control her behavior. This was relevant for the evaluation of the prosecutor's hypothesis: J.F., the prosecutor claimed, would have impulsively smothered the newborn child to death immediately after childbirth. Thus, the pathological features identified with the psychiatric and neuropsychological evaluation pathologically impulsivity, antisocial tendencies, lack of planningare causally linked to the crime, thus providing the basis for an insanity defense.

In order to provide a better understanding of the biological basis of the mental disease identified at a behavioral level, we carried out a structural brain analysis using VBM (Ashburner and Friston, 2000; Mechelli et al., 2005), and a genetic analysis, in order to shed light on the neural and genetic markers predisposing J.F to the development of impulsive psychiatric disorders. We found that J.F. behavioral syndrome was accompanied by a reduced gray matter in the frontal lobe, and an unfavorable genetic profile.

More precisely, we applied VBM (Ashburner and Friston, 2000; Mechelli et al., 2005) in order to assess brain regions with a reduced gray matter density. The VBM analysis revealed reduced gray matter volume in the left PFC of J.F. relative to a control group of healthy subjects. The strongest effects were detected in the left middle frontal gyrus (Figure 1) and the left superior frontal gyrus (Figure 2). In these regions, J.F.'s gray matter was lower than any of the other healthy controls' gray matter. It is well established that individuals with PFC damage show poor behavioral control (Aron et al., 2003; Li et al., 2006). More precisely, it is well known that the dorsolateral region of the PFC, that includes inferior, medium and superior gyri, is crucial for response suppression and the inhibition of impulsive response. Although some studies found an association only between the right PFC and response inhibition (Aron et al., 2003), others reported that the integrity of the left PFC is critical for the successful implementation of inhibitory control over behavioral responses (Swick et al., 2008).

As regard to molecular genetics, we genotyped the following polymorphisms: 5HTTLPR (SCL6A4), STin2 (SCL6A4), rs4680 (COMT), MAOA-uVNTR, and DRD4-2/11.

The short allele of 5HTTLPR polymorphism plays a role in reducing the activity (30-40\%) of the serotonin transporter (5-HTT). Numerous studies reported a correlation between short allele of the 5-HTT promoter polymorphism and a major predisposition to violent and impulsive behavior (Virkkunen et al., 1995; Haberstick et al., 2006; Sakai et al., 2006), particularly when associated with alcohol abuse (Hallikainen et al., 1999) and heroin abuse (Gerra et al., 2004). 

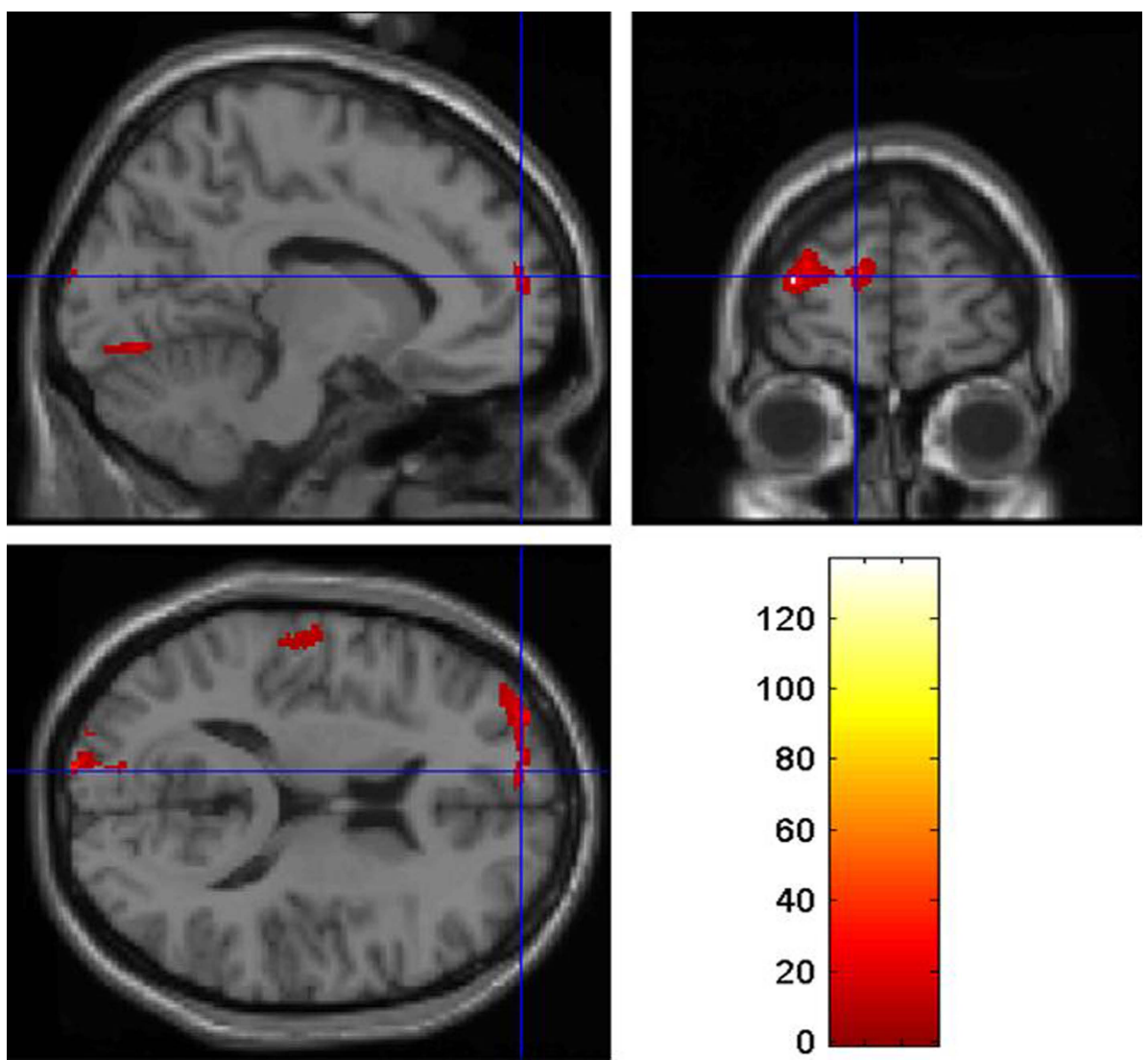

FIGURE 2 | Region of the left superior frontal gyrus showing reduced gray matter density in J.F. relative to healthy controls, at $p<0.05$ (corrected for multiple comparisons).

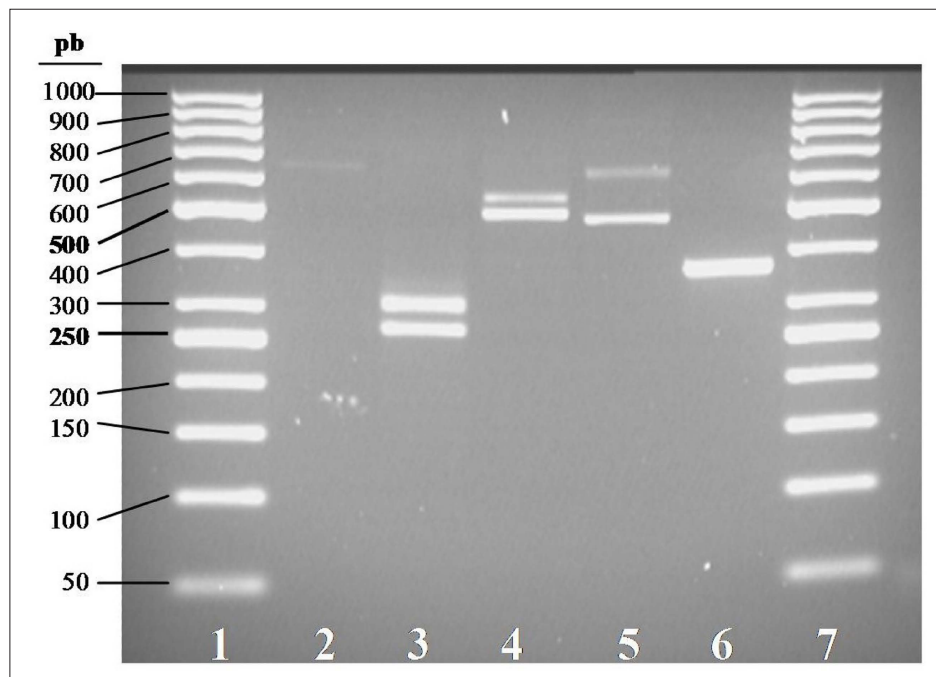

Lane 1: GeneRuler 50 bp DNA Ladder (Fermentas)

Lane 2: COMT (1 band: $626 \mathrm{bp}$ long)

Lane 3: STin2 (2 bands: 299 and 265bp long)

Lane 4: 5HTTLPR (2 bands: 529 and 485bp long)

Lane 5: DRD4 (2 bands: 614 and 470bp long)

Lane 6: MAOA-uVNTR (1 band: 354bp long)

Lane 7: GeneRuler 50 bp DNA Ladder (Fermentas)

FIGURE 3 | Electrophoretic patterns of PCR products obtained from J.F's DNA. STin2, 5HTTLPR, DRD4 (lanes 3, 4, and 5) show two bands with different molecular weights, each corresponding to a different allele (heterozygous genotype). MAOA-uVNTR (lane 6) shows a single band corresponding to an homozygous genotype. COMT (lane 2) shows a single band, as expected, since it is a SNP.
Another polymorphism in the SCL6A4 gene, found to be associated with various forms of psychiatric illnesses, is the STin2, which consists of three alleles respectively containing nine (STin2.9), 10
(STin2.10), and 12 (STin2.12) copies of the variable number of tandem repeat (VNTR) region. STin 2.12 is supposed to enhance the efficiency of the gene transcription (MacKenzie and Quinn, 1999) 


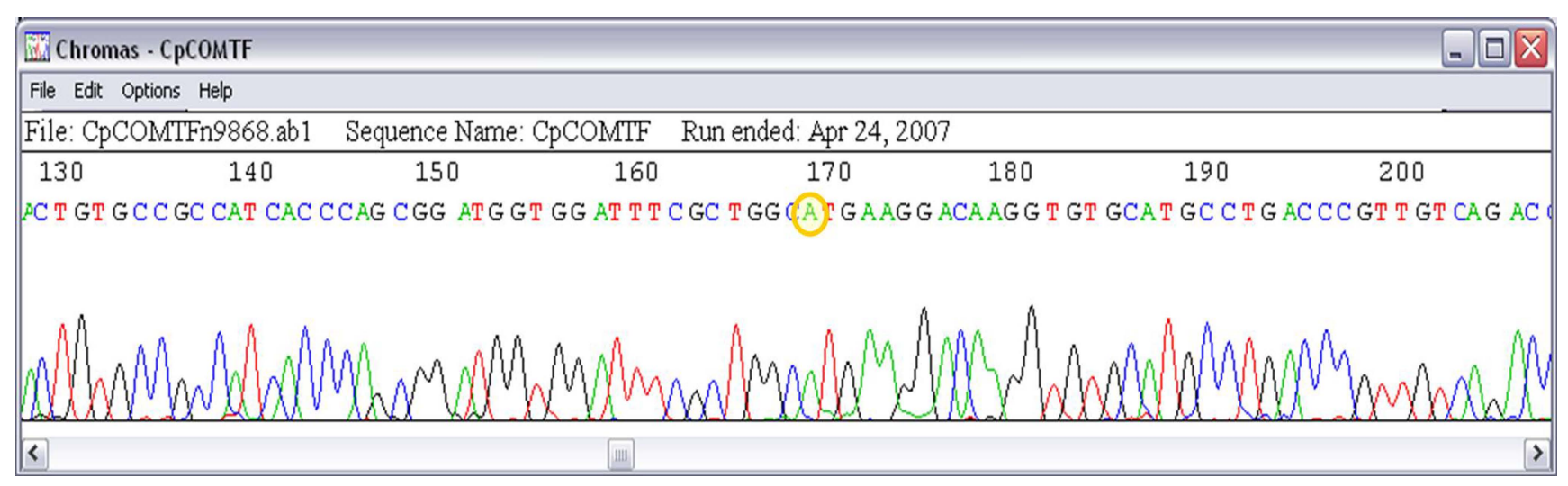

FIGURE 4 | Electropherogram showing the genotype A/A (yellow circle) of COMT-rs 4680 polymorphism.

Table 3 | Genotypes identified in J.F.

\begin{tabular}{lll}
\hline Polymorphism & J.F.'s genotype & \\
\hline 5HTTLPR & L (Long) S (Short) & Heterozygote \\
STin2 (SCL6A4) & STin2-10 STin2-12 & Heterozygote \\
rs4680 (COMT) & A (Met) A (Met) & Homozygote \\
MAOA-uVNTR & MAOA-4 MAOA-4 & Homozygote \\
DRD4-2/11 & DRD4-4 DRD4-7 & Heterozygote \\
\hline
\end{tabular}

and it was found to be associated with a greater susceptibility to develop various mental illnesses, like schizophrenia (Fan and Sklar, 2005), obsessive-compulsive disorder (Baca-Garcia et al., 2007), and anxiety disorders (Ohara et al., 1999). A reduced frequency of STin2.10 allele was found to correlate with aggressive behavior in children (Davidge et al., 2004).

Catechol-O-methyltransferase (COMT) is an important enzyme that participates in the metabolic inactivation of dopamine and norepinephrine. COMT inactivates catecholamines by catalyzing $S$-adenosyl-L-methionine dependent methyl conjugation (Axelrod and Tomchick, 1958). Lachman et al. (1996) and Lotta et al. (1995), identified a common functional polymorphism at COMT codon 158 that results in substantial differences in enzyme activity. One allele encodes a methionine at codon 158 (158Met) and the other allele a valine (158Val). Homozygotes for 158Val have three to four-fold higher levels of activity than 158Met homozygotes, and heterozygotes have an intermediate level of activity. Recent investigations have supported an association between the low activity allele (L-Low) Met and aggressive behavior (Kotler et al., 1999; Strous et al., 2003; Volavka et al., 2004).

MAOA, which plays a vital role in degradation of neurotransmitters such as serotonin, norepinephrine, and dopamine, contains a polymorphism in its promoter region (MAOA-uVNTR) that affects transcriptional efficiency. This polymorphism, which is located 1.2-kb upstream of the MAOA coding sequence, consists of a 30-bp repeated sequence present in 3, 3.5, 4, or 5 copies (Sabol et al., 1998). Alleles with 3.5 or 4 copies of the repeated sequence are transcribed two to ten times more efficiently than those with 3 or 5 copies of the repeat. Low-activity alleles have been associated with violent and aggressive behavior in males (Caspi et al., 2002; Gerra et al., 2004; Huang et al., 2004; Volavka et al., 2004; Craig, 2007; Reif et al.,
2007), but not in females (Huang et al., 2004; Williams et al., 2009). The localization of MAOA on chromosome X might in part explain this observed difference between sexes. Heterozygous females, in fact, because of the random epigenetic inactivation of one of the two MAOA alleles, often show an intermediate phenotype which may lead to misleading results in association studies.

Sjöberg et al. (2007), however, have suggested that the MAOA high-activity allele with four repeats may predict criminal behavior in women through an interaction with psychosocial adversity. These findings, although preliminary and in need of replication in larger samples of subjects, suggest the existence of gender specific biological mechanisms related to the MAOA genotype effects on behavior. Sex hormones, for instance, might contribute to the sex differences in MAOA effects by modulating MAOA expression. Testosterone, in fact, correlates positively with aggression and violent crime (Scerbo and Kolko, 1994; Dabbs et al., 1995), while estrogens and progesterone have been shown to significantly reduce MAOA transcription in the brain of rhesus monkeys (Gundlah et al., 2002).

The human dopamine receptor D4 (DRD4) gene contains a functional polymorphism consisting of two to ten 48 -bp repeats in the third exon (Van Tol et al., 1992). The variant allele containing 7 repeats $(7 \mathrm{R})$ has been associated with hyperactive and aggressive behavior (DeYoung et al., 2006), as well as highly impulsive behavior and novelty seeking (Ebstein et al., 1996).

Results from J.F.'s DNA genotyping showed that, for each of the examined polymorphisms, including the MAOA-uVNTR, the defendant had one or both the alleles found to be significantly associated with aggressive or violent behavior.

The forensic evaluation on J.F. highlighted both brain and gene correlates predisposing to violent and aggressive behavior. This provided evidence that the symptoms shown by J.F., namely pathological impulsivity, high sensation-seeking, impaired behavioral control, poor understanding of others' emotional state, and a lack of planning ability, had a "hard" biological basis. The defendant had high vulnerability to impulsive and aggressive behavior due to her genetic makeup and to the anomalous PFC. It is also likely that the adverse context where the alleged crime was committed had a crucial role in triggering the impulsive response. It is well known that environmental factors, such as stressful environments, have a key role in determining violence and aggressive behavior (see Craig, 2007 for a review). More 
precisely, stress is a crucial factor in precipitating aggressive episodes, and individuals vary in their ability to cope with stressful environments depending on various factors such as their genetic make-up, the presence of a psychiatric disease and/or brain alterations (Craig 2007). According to the prosecutor, J.F. smothered to death her newborn child immediately after delivery, which she underwent alone in the bathroom of her boyfriend's apartment. Delivery should be considered a stressful event, especially when the delivering woman is alone (Hodnett, 2002). In our opinion, the adverse environment in which the delivery was undertaken might have had a strong influence in triggering the impulsive reaction, especially in an individual with high vulnerability as the defendant. However, these considerations have only a speculative nature.

\section{REFERENCES}

Aron, A. R., Fletcher, P. C., Bullmore, E. T., Sahakian, B. J., and Robbins, T. W. (2003). Stop-signal inhibition disrupted by damage to right inferior frontal gyrus in humans. Nat. Neurosci. 6, 115-116.

Ashburner, J., and Friston, K. J. (2000). Voxel-based morphometry-the methods. NeuroImage 11, 805-821.

Axelrod, J., and Tomchick, R. (1958). Enzymatic O-methylation of epinephrine and other catechols. J. Biol. Chem. 233, 702-705.

Baca-Garcia, E., Vaquero-Lorenzo, C., Diaz-Hernandez, M., RodriguezSalgado, B., Dolengevich-Segal, H., Arrojo-Romero, M., Botillo-Martin, C., Ceverino, A., Piqueras, J. F., Perez-Rodriguez, M. M., and SaizRuiz, J. (2007). Association between obsessive-compulsive disorder and a variable number of tandem repeats polymorphism in intron 2 of the serotonin transporter gene. Prog. NeuroPsychopharmacol. Biol. Psychiatry 31, 416-420.

Belleville, S., Peretz, I., and Malenfant, D. (1996). Examination of the working memory components in normal aging and in dementia of the Alzheimer type. Neuropsychologia 34, 195-207.

Blair, R. J. R., and Cipolotti, L. (2000) Impaired social response reversal. A case of 'acquired sociopathy'. Brain 123, 1122-1141.

Burgess, P. W., and Shallice, T. (1996). Response suppression, initiation and strategy use following lobe lesions, Neuropsychologia 34, 263-273.

Butcher,J.N.,Dahlstrom, W.G., Graham,J. R., Tellegen A., and Kaemmer,B. (1989). MMPI2: Manual for Administration and Scoring Minneapolis, MN: University of Minnesota Press.

Caspi, A., McClay, J., Moffitt, T.E., Mill, J., Martin, J., Craig, I. W., Taylor, A., and Poulton, R. (2002). Role of genotype in the cycle of violence in maltreated children. Science 297, 851-854.
Cases, O., Seif, I., Grimsby, J., Gaspar, P., Chen, K., Pournin, S., Muller, V., Agnet, M., Babinet, C., and Shih, J. C. (1995). Aggressive behavior and altered amounts of brain serotonin and norepinephrine in mice lacking MAOA. Science 268, 1763-1766.

Craig, I. W. (2007). The importance of stress and genetic variation in human aggression. BioEssays 29, 227-236.

Dabbs, J. M., Carr, T. S., Frady, R. L., and Riad, J. K. (1995). Testosterone, crime, and misbehavior among 692 male prison inmates. Pers. Individ. Dif. 18, 627-633.

Davidge, K. M., Atkinson, L., Douglas, L., Lee, V., Shapiro, S., Kennedy, J. L., and Beitchman, J. H. (2004). Association of the serotonin transporter and 5HT1Dbeta receptor genes with extreme, persistent and pervasive aggressive behaviour in children. Psychiatr. Genet. 14, 143-146.

Della Sala, S., MacPherson, S. E., Phillips, (2003). How many camels are there in Italy? Cognitive estimates standardised on the Italian population. Neurol. Sci. 24, 10-15.

DeYoung, C. G., Peterson, J. B., Se'guin, J. R., Mejia, J. M., Pihl, R. O., Beitchman, J.H., Jain, U., Tremblay, R. E., Kennedy, J. L., and Palmour, R. M. (2006). The dopamine $\mathrm{D} 4$ receptor gene and moderation of the association between externalizing behaviour and IQ. Arch. Gen. Psychiatry 63, 1410-1416.

Ebstein, R. P., Novick, A., Umansky, R., Priel, B., Osher, Y., Blaine, D., Bennett, E. R., Nemanov, L., Katz, M., and Belmaker, R. H. (1996). Dopamine D4 receptor (DRD4) Exon III polymorphism associated with the human personality trait of Novelty Seeking. Nat. Gen. 12, 78-80.

Fan, J. B., and Sklar, P. (2005). Metaanalysis reveals association between serotonin transporter gene STin2 VNTR polymorphism and schizophrenia. Mol. Psychiatry 10, 928-938. L. H., Sacco, L., and Spinnler, H.
In sum, we have applied neuropsychological, imaging and molecular genetics to the study of diminished responsibility case. Our opinion is that the use of these techniques may improve forensic psychiatric assessment and may be used to depict a full "gene-to-brain-to-behavior" description of the case. Importantly, this approach may reduce uncertainty in forensic psychiatric evaluations and reduce the probability that psychiatric symptoms are the result of malingering.

\section{ACKNOWLEDGMENTS}

This work was supported by the Centro Universitario Internazionale, Monte San Savino, Italy, and the Cassa di Risparmio di Padova e Rovigo (Cariparo), Italy.

Gerra, G., Garofano, L., Bosari, S., Pellegrini, C., Zaimovic, A., Moi, G., Bussandri, M., Moi, A., Brambilla, F., Mameli, A., Pizzamiglio, M., and Donnini, C. (2004). Analysis of monoamine oxidase A (MAO-A) promoter polymorphism in male heroin-dependent subjects: behavioral and personality correlates. J. Neural Transm. 111, 611-621.

Grafman, J., Schwab, K., Warden, D., Pridgen, A., Brown, H. R., and Salazar, A. M. (1996). Frontal lobe injuries, violence, and aggression: a report of the Vietnam Head Injury Study. Neurology 46, 1231-1238.

Gundlah, C., Lu, N. Z., and Bethea, C. L. (2002). Ovarian steroid regulation of monoamine oxidase-A and -B mRNAs in the macaque dorsal raphe and hypothalamic nuclei. Psychopharmacology 160, 271-282.

Haberstick, B. C., Smolen, A., and Hewitt, J. K. (2006). Family-based association test of the 5HTTLPR and aggressive behaviour in a general population sample of children. Biol. Psychiatry 59, 836-843.

Hallikainen, T., Saito, T., Lachman, H. M., Volavka, J., Pohjalainen, T., Ryynanen, O. P., Kauhanen, J., Syvalahti, E., Hietala, J., and Tiihonen, J. (1999). Association between low activity serotonin transporter promoter genotype and early onset alcoholism with habitual impulsive violent behaviour. Mol. Psychiatry 4, 385-388.

Harlow, J. (1848). Passage of an iron bar through the head. Boston Med. Surg. J. 13, 389-393.

Heils, A., Teufel, A., Petri, S., Stober, G., Riederer, P., Bengel, D., and Lesch, K. P. (1996). Allelic variation of human serotonin transporter gene expression. J. Neurochem. 66, 2621-2624.

Herpetz, S. C., Dietrich, T. M., Wenning, B., Krings, T., Erberich, S. G., Willmes, K., Thron, A., and Sass, H. (2001). Evidence of abnormal amygdala functioning in borderline personality disorder: a functional MRI study. Biol. Psychiatry 50, 292-298.

Hodnett, E. D. (2002). Pain and women's satisfaction with the experience of childbirth: a systematic review. Am. J. Obstet. Gynecol. 186, S160-S172.

Huang, Y. Y., Cate, S. P., Battistuzzi, C., Oquendo, M. A., Brent, D., and Mann, J. J. (2004). An association between a functional polymorphism in the monoamine oxidase a gene promoter, impulsive traits and early abuse experiences. Neuropsychopharmacology 29, 1498-1505.

Kotler, M., Barak, P., Cohen, H., Averbuch, I. E., Grinshpoon, A., Gritsenko, I., Nemanov, L., and Ebstein, R. P. (1999). Homicidal behaviour in schizophrenia associated with a genetic polymorphism determining low catechol O-methyltransferase (COMT) activity. Am. J. Med. Genet. 88, 628-633.

Lachman, H. L., Papolos, D. F., Saito, T., Yu, Y. M., Szumlanski, C. L., and Weinshilboum, R. M. (1996). Human catechol-O-methyltransferase pharmacogenetics: description of a functional polymorphism and its potential application to neuropsychiatric disorders, Pharmacogenetics 6, 243-250.

Li, C. R., Huang, C., Constable, R. T., and inhibition in a stop-signal task: neural correlates independent of signal monitoring and post-response processing. J. Neurosci. 26, 186-192.

Lichter, J. B., Barr, C. L., Kennedy, J. L., Van Tol, H. H. M., Kidd, K. K., and Livak, K. J. (1993). A hypervariable segment in the human dopamine receptor D4 (DRD4) gene. Hum. Mol. Genet. 2, 767-773.

Lilienfeld, S. O., and Widows, M. R. (2005). Psychopathic Personality Inventory Revised. Professional Manual. Florida, USA: Psychological Assessment Resources, Inc.

Lotta, T., Vidgren, J., Tilgmann, C., Umanen, I., Melen, K., and Julkunen, I. (1995). Kinetics of human soluble and Sinha, R. (2006). Imaging response 
membrane bound catechol-O-methyltransferase: a revised mechanism and description of the thermolabile variant of the enzyme. Biochemistry 34, 4202-4210.

MacKenzie, A., and Quinn, J. (1999). A serotonin transporter gene intron 2 polymorphic region, correlated with affective disorders, has allele dependent differential enhancer-like properties in the mouse embryo. Proc. Natl. Acad. Sci. U.S.A. 96, 15251-15255.

Mechelli, A., Price, C. J., Friston, K. J., and Ashburner, J. (2005) Voxel-based morphometry of the human brain: methods and applications. Curr. Med. Imaging Rev. 1, 105-113.

Meyer-Lindenberg, A., Buckholtz, J. W., Kolachana, B., Hariri, A. R., Pezawas, L., Blasi, G., Wabnitz, A., Honea, R., Verchinski, B., Callicott, J. H., Egan, M., Mattay, V., and Weinberger, D. R. (2006). Neural mechanisms of genetic risk for impulsivity and violence in humans. Proc. Natl. Acad. Sci. U.S.A. 103, 6269-6274.

Miller, P. R., Dasher, R., Collins, R., Griffiths, P., and Brown, F. (2001). Inpatient diagnostic assessments, I: accuracy of structured vs unstructured interviews. Psychiatry Res. 105, 255-264.

Mobbs, D., Lau, H. C., Jones O. D., and Frith, C.D. (2007). Law, responsibility, and the brain. PLoS Biol. 5, 693-700. doi:10.1371/journal.pbio.0050103.

Mondini, S., Mapelli, D., Vestri, A., and Bisiacchi, P. (2003). Esame Neuropsicologico Breve. Padova: Raffaello Cortina.

Mühlau, M., Wohlschläger, A. M., Gaser, C., Valet, M., Weindl, A., Nunnemann, S., Peinemann, A., Etgen, T., and Ilg, R. (2009). Voxel-based morphometry in individual patients: a pilot study in early Huntington disease. Am. J. Neuroradiol. 30, 539-543.

Ogilvie, A. D., Battersby, S., Bubb, V. J., Fink, G., Harmar, A. J., Goodwim,
G. M., and Smith, C. A. (1996). Polymorphism in serotonin transporter gene associated with susceptibility to major depression. Lancet 347, 731-733.

Ohara, K., Suzuki, Y., Ochiai, M. Tsukamoto, T., Tani, K., and Ohara, K. (1999). A variable-numbertandem-repeat of the serotonin transporter gene and anxiety disorders. Prog. Neuropsychopharmacol. Biol. Psychiatry 23, 55-65.

Prior, M., Marchi S., and Sartori, G. (2003). Cognizione Sociale e Comportamento, Vol. I. padova Upsel Domeneghini Editore.

Raine, A. (2008). From genes to brain to antisocial behaviour. Curr. Dir. Psychol. Sci. 17, 323-328.

Raine, A., Buchsbaum, M., and LaCasse, L. (1997). Brain abnormalities in murderers indicated by positron emission tomography. Biol. Psychiatry 42, 495-508.

Raine, A., Lencz, T., Bihrle, S., LaCasse, L., and Colletti, P. (2000). Reduced prefrontal gray matter volume and reduced autonomic activity in antisocial personality disorder. Arch. Gen. Psychiatry 57, 119-127.

Reif, A., Rosler, M., Freitag, C. M. Schneider, M., Eujen, A., Kissling, C., Wenzler,D.,Jacob, C.P., Retz-Junginger, P., Thome, J., Lesch, K. P., and Retz, W (2007). Nature and nurture predispose to violent behaviour: serotonergic genes and adverse childhood environment. Neuropsychopharmacology 32, 2375-2383.

Reitan, R. M. (1958). Validity of the trail making test as an indicator of organic brain damage. Percept. Motor Skill 8, 271-276.

Sabol, S. Z., Hu, S., and Hamer, D. (1998) A functional polymorphism in the monoamine oxidase A gene promoter. Hum. Genet. 103, 273-279.

Sakai, J. T., Young, S. E., Stallings, M. C. Timberlake, D., Smolen, A., Stetler,
G. L., and Crowley, T. J. (2006). Casecontrol and within-family tests for an association between conduct disorder and 5HTTLPR. Am. J. Med. Genet. B Neuropsychiatr. Genet. 141, 825-832.

Scerbo, A. S., and Kolko, D. J. (1994). Salivary testosterone and cortisol in disruptive children: relationship to aggressive, hyperactive, and internalizing behaviors. J. Am. Acad. Child Adolesc. Psychiatry 33, 1174-1184.

Sjöberg, R., Nilsson, K., Wargelius, H., Leppert, J., Lindström, L., Oreland, L. (2007). Adolescent girls and criminal activity: role of MAOA-LPR genotype and psychosocial factors. Am. J. Med. Genet. B Neuropsychiatr. Genet. 144B, 159-164.

Spinnler, H., and Tognoni, G. (1987). Standardizzazione e taratura italiana di test neuropsicologici. Ital. J. Neurol. Sci. 6, 47-50.

Strous, R. D., Nolan, K. A., Lapidus, R. Diaz, L., Saito, T., and Lachman, H. M. (2003). Aggressive behaviour in schizophrenia is associated with the low enzyme activity COMT polymorphism: a replication study. Am. J. Med. Genet. B Neuropsychiatr. Genet. 120, 29-34.

Swick, D., Ashley, V., and Turken, A. U. (2008). Left inferior frontal gyrus is critical for response inhibition, $B M C$ Neurosci. 9, 102.

Van Tol, H. H., Wu, C. M., Guan, H. C. Ohara, K., Bunzow, J. R., Civelli, O. Kennedy, J., Seeman, P., Niznik, H. B., and Jovanovic, V. (1992). Multiple dopamine D4 receptor variants in the human population. Nature 358, 149-152.

Virkkunen, M., Goldman, D., Nielsen, D. and Linnoila, M. (1995). Low brain serotonin turnover rate (low CSF 5H-IAA) and impulsive violence. $J$. Psychiatry Neurosci. 20, 271-275.

Volavka, J., Bilder, R., and Nolan, K. (2004). Catecholamines and aggression: the role of COMT and MAO polymorphisms. Ann. N.Y. Acad. Sci. 1036, 393-398.

Wahlund, K., and Kristiansson, M. (2009). Aggression, psychopathy and brain imaging - Review and future recommendations. Int. J. Law Psychiatry 32, 266-271.

Wechsler, D. (1945).A standardized memory scale for clinical use. J. Psychol. 19, 87-95.

Williams, L. M., Gatt, J. M., Kuan, S. A., Dobson-Stone, C., Palmer, D. M., Paul, R. H., Song, L., Costa, P. T., Schofield, P. R., and Gordon, E. (2009). A polymorphism of the MAOA gene is associated with emotional brain markers and personality traits on an antisocial index. Neuropsychopharmacology 34, 1797-1809.

Züchner, S., Roberts, S. T., Speer, M. C., and Beckham, J. C. (2007). Update on psychiatric genetics. Genet. Med. 9, 332-340

Conflict of Interest Statement: The authors declare that the research was conducted in the absence of any commercial or financial relationships that could be construed as a potential conflict of interest.

Received:03 February 2010; paper pending published: 11 July 2010; accepted: 11 August 2010; published online: 13 October 2010. Citation: Rigoni D, Pellegrini S, Mariotti V, Cozza A, Mechelli A, Ferrara SD, Pietrini $P$ and Sartori G (2010) How neuroscience and behavioral genetics improve psychiatric assessment: Report on a violent murder case. Front. Behav. Neurosci. 4:160. doi: 10.3389/fnbeh.2010.00160

Copyright (c) 2010 Rigoni, Pellegrini, Mariotti, Cozza, Mechelli, Ferrara, Pietrin and Sartori. This is an open-access article subject to an exclusive license agreement between the authors and the Frontiers Research Foundation, which permits unrestricted use, distribution, and reproduction in any medium, provided the original authors and source are credited. 